\title{
AN EXAMINATION OF THE ESSENTIAL ASPECTS, IN EXECUTION OF ENTERPRISE RESOURCE PLANNING IN MANUFACTURING AND PRODUCTION INDUSTRIES
}

\section{SRI RANJINI. S}

Assistant. Professor, Department. of Management and Commerce, Amrita University, Mysuru Campus, Karnataka, India

ABSTRACT
Manufacturing and Production Industries in India, provide the most diligent profession and they are also the
predecessor in emerging novel thought in the field of industry. They do not merely participate in possessing a
fundamental responsibility, for providing a huge extent of work opportunity but also assist in industrialization of rural
areas in India. Occasionally Manufacturing and Production Industries in India are harmonizing to bulky engineering
industries as additional units. This segment contributes enormously to the socio-economic expansion of the country.
Manufacturing and Production industries have developed immensely in the last five decades. In spite of elevated passion
and fundamental capabilities to breed, there is quite a quantity of troubles faced by manufacturing and production
industries; one of them is the 'technological obsolescence'. This sector in order to outcome this challenge must make
advances in the field of engineering and technology. Adoption of Information and Communication Technology (ICT) in
their business process can enhance their productivity and global competency in the national and international market.
In this connection Enterprise Resource Planning plays a vital role in the Manufacturing and Production industry's
business process strategy. Hence, there is a need for the motivation to implement ERP and find out whether the current
ICT solution which the industries are using is adequate for their strategy. In this paper the researcher is trying to find
out which ERP vendors does the manufacturing and production sectors have a preference, what are the features of the
ERP system and the implementation methodology chosen and have they met their business goals and user satisfaction.
KEYWORDS: Mechanical and Production Industry, Enterprise Resource Planning \& Technology

Received: Oct 03, 2017; Accepted: Oct 23, 2017; Published: Nov 22, 2017; Paper Id.: IJMPERDDEC201744

\section{INTRODUCTION}

Manufacturing and Production industries are significant for the expansion and progress of India's monetary improvement. Information Technology has turned out to be an essential fraction in any kind of venture. Nowadays, machinery and the up-gradation of the related technology play a critical task in increasing the competitiveness and in promoting the growth of manufacturing and production industries. The business process has turned out to be multifaceted every day and has necessitated additional in-house data flow for decision making, timely information generation, inventory management and resource management. In this consideration, business managers require well-organized information systems to take care of the enormous data flow and deal with the information produced by the company consequential in enhancement of decrease in expenditure, increase in the productivity and satisfaction of the customer. ERP is an incorporated arrangement which has the possession of the transaction processing to decision support system, the whole thing in a single basin. In contrast to supplementary information systems such as 'spreadsheet' which has investigative instrument that sustain decision making and 
'Tally' an accounting package, ERP proposes an integrated parcel where the managers can proficiently use it to get better internal communication, productivity and get a visually pleasant information for decision making.

Indian Manufacturing and Production industries are looking for technologies like cloud computing, analytics and mobile elucidation to advance operations and grow to be more well-organized, according to a fresh research account by Circle Research, according to a press release issued by enterprise application software company SAP, which sponsored the research. To continue efficiently in the market and to develop the productivity as per the competiveness are forcing the manufacturing and production industries to entirely re-evaluate the long-established business models and implement cutting edge technologies like cloud and big data, wherever these technologies help these industries to achieve business success and fulfill their ambitions. In this paper the researcher is attempting to examine the preference of manufacturing and production industries for SAP and how many have put into use ERP for their production and to discover if ERP is supportive for the functioning in their organizations.

\section{LITERATURE REVIEW}

- Davide Aloini et al (2013) in their article have said that, even though ERP systems have acknowledged interest in organizations, ERP projects are frequently found to be multifaceted and unsafe, to put into practice in business enterprises. The significance and risk of ERP makes it imperative for organization to focus on activities to make ERP execution victorious.

- Moutaz Haddara and Ondrej Zach (2011) in their article are of the opinion that, owing to the close to saturation of ERPs in Large enterprises (LE) the sellers of ERPs are centering on SMEs (small and medium size enterprises). Due to globalization and large flow of information across and within SMEs, many SMEs are now going for adopting ERP in their business process

- Andre Luiz Pestana de Oliveira and Marco Antonio Pinheiro da Silveira (2010), in their article are of the opinion that the ERPs implemented in the companies, have met the expectations of the production managers. They conducted a survey, within the State of Sao Paulo, Brazil, through an exploratory research. But, they also noted that numerous actions of the ERP are not utilized by the companies. They have also noted that, as there is an increase in the number of activities used, there is an increase in the level of perception of the needs being met.

- Aman Deep et al (2008) in their paper present the conclusion of the research, which was accepted as a part of a project for selection of an ERP system in SME. It builds up a skeleton or methodology, for selection of ERP

- Valerie Botta - Genoulaz and Pierre - Alain Millet (2004) has said that, of late even service organizations have empowered themselves, by the implementation of ERP systems. They have even started using elucidation which was building up for manufacturing companies. This paper gives an insight on, how services can also approach ERP implementation.

- Chwen Sheu, Bongsug Chae and Chen-Lung Yang (2004) say that, international implementation of ERP introduces an additional aspect of difficulty, into the already complicated environment of implementing ERP, in the framework of universal information management. This study has assessed many issues, which are vital for the successful implementation of international ERP. 
- With respect to Aghazadeh (2003) ERP, had a hard-hitting commencement, but ERP was able to conquer the complexity and has sustained the environment, to become more suitable for companies by providing them the essential information. But companies must adjust themselves, to the rules and regulations of these systems; therefore it is appropriate to question the user's judgment, about their needs being met or not.

- Jeff K Stratman and Aleda V Roth (2002), this paper describes eight ERP capability builds. They describe ERP competence as an assortment of technical, managerial and organizational talent and proficiency as background, to improve the performance of business, after the implementation of ERP systems. Organizations are increasingly adopting ERP systems, to improve their responses to the changing markets.

- Davenport (2002) says that, ERPs are integrated application packages, which are formed to congregate most of the information requirements of the company.

- Helmut Klaus, Michael Rosemann and Guy G Gable (2000) have said that, eventhough ERP has added more reputation in the information systems over the past few years, and in practice it has become an important trend, the augmented simplicity of the concept of ERP can also provide advantage in other associated fields of knowledge.

- Souza (2000) say that ERPs are prevailing IT solutions for companies and if, they are correctly put into practice ERP may tender innumerable advantages to the companies.

- Correa and Gianesi (1994) and Gupta and Kohli (2006) says that, ERP's spotlight is on process of business and not on the operational vicinity of an organization.

\section{METHODOLOGY}

The most important objective of this research is, to ascertain the essential aspects considered by the company in choosing, execution and approval of ERP in their companies. An investigation was accomplished in Small and Medium Scale production and manufacturing units in South India. Data was collected from the production \& manufacturing units which have put into practice and also not put into practice the ERP systems. A sample size of 40 units was chosen by the technique of 'simple random sampling'. Data was gathered by means of a questionnaire that was prepared after probing the relevant texts and related indexes. Only one survey questionnaire was sent to an ERP organization user. The respondents were manager, inventory manager, production manager and marketing executive. Since some of the units did not return the questionnaire and some questionnaires returned were only partially filled, the researcher had to discard 12 questionnaires. Finally the analysis was performed only for 28 companies. To make sure that the study must be integrated into the survey the past work of the researches were reviewed.

\section{OBJECTIVES}

- To examine the benefits derived by implementing ERP

- To study the methodology of implementation of the ERP

- To analyze the most preferred ERP by the manufacturing and production organizations

Based on the above objectives the researcher has formulated the following hypothesis which was tested using SPSS tools. 


\section{Hypothesis}

$\mathbf{H}_{1}$ : Implementing ERP systems improves the efficiency of the productivity in the company

$\mathbf{H}_{2}$ : ERP systems were implemented using the Big Bang methodology

$\mathbf{H}_{3}$ : SAP is the most preferred ERP in the manufacturing and production organizations

\section{ANALYSIS AND RESULTS}

\section{Advantages}

ERP systems are utilized to present the identical, efficient and precise information across diverse tasks and this is why its relevance is to manufacturing and production units. The benefit of these systems is that identical information is observed by all the employees in various departments. The ERP system also goes ahead with this efficient and correct information to the subsequently concerned section. Apart from the low cost ownership the implementation of ERP systems gives more advantages to the organization like increased productivity, reduced operational cost, improved internal communication and improved customer service and order fulfillment as shown in the Figure 1 and Table 1

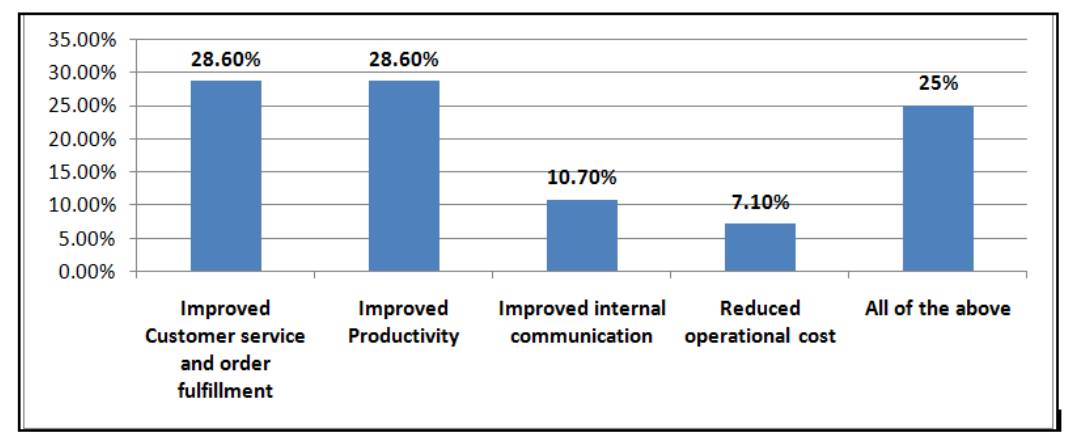

Figure 1: Advantages of ERP Implementation

Table 1: Advantages in ERP System Implementation

\begin{tabular}{|c|l|c|c|c|c|}
\hline \multicolumn{2}{|c|}{} & Frequency & Percent & $\begin{array}{c}\text { Valid } \\
\text { Percent }\end{array}$ & $\begin{array}{c}\text { Cumulative } \\
\text { Percent }\end{array}$ \\
\hline \multirow{7}{*}{ Valid } & $\begin{array}{l}\text { Improved Customer service } \\
\text { and order fulfillment }\end{array}$ & 8 & 28.6 & 28.6 & 28.6 \\
\cline { 2 - 6 } & Improved Productivity & 8 & 28.6 & 28.6 & 57.2 \\
\cline { 2 - 6 } & $\begin{array}{l}\text { Improved internal } \\
\text { communication }\end{array}$ & 3 & 10.7 & 10.7 & 67.9 \\
\cline { 2 - 6 } & Reduced operational cost & 2 & $\mathbf{0 7 . 1}$ & $\mathbf{0 7 . 1}$ & $\mathbf{7 5 . 0}$ \\
\cline { 2 - 6 } & All of the above & 7 & $\mathbf{2 5 . 0}$ & $\mathbf{2 5 . 0}$ & $\mathbf{1 0 0 . 0}$ \\
\cline { 2 - 6 } & Total & 28 & 100.0 & 100.0 & \\
\hline
\end{tabular}

The Hypothesis H1:

H1: Implementing ERP systems improves the efficiency of the productivity in the company 


\section{Chi - Square Test}

\begin{tabular}{|l|c|c|c|}
\hline & Value & Df & $\begin{array}{c}\text { Asymp. } \\
\text { Sig } \\
\text { (2-Sided) }\end{array}$ \\
\hline Pearson Chi-Square & 10.814 & 4 & 0.017 \\
\hline Likelihood Ratio & 12.371 & 4 & .009 \\
\hline Linear by Linear Association & 5.447 & 1 & .009 \\
\hline Number of Valid Cases & $\mathbf{2 8}$ & & \\
\hline
\end{tabular}

The Chi - Square test gives the Pearson Chi-Square value of 10.814 at 4 degrees of freedom and the level of significance is 0.017 which is less than 0.05 . Since the p value is less than 0.05 ie. $\mathrm{P}<0.05$, the null hypothesis is rejected and the research hypothesis is accepted. Therefore implementing ERP systems improves the efficiency of the productivity in the company. The first hypothesis is proved true.

\section{APPROACHES TOWARDS IMPLEMENTATION}

When a fresh system needs to be implemented in an organization there are many ways they can implement. The different ways are:

Big Bang approach where all the modules of the system are implemented together and the go live date for all the sections/departments will be the same. In phased approach the adaptation happens in sequential manner, in parallel approach the old and new system will be alive for some time until the end users become acquainted to the new system. Hybrid approach combines both phased and parallel approach. According to the study, most of the organizations used Big Bang approach to implement the ERP system. The frequency of these approaches is shown in the figure 2 and table 2.

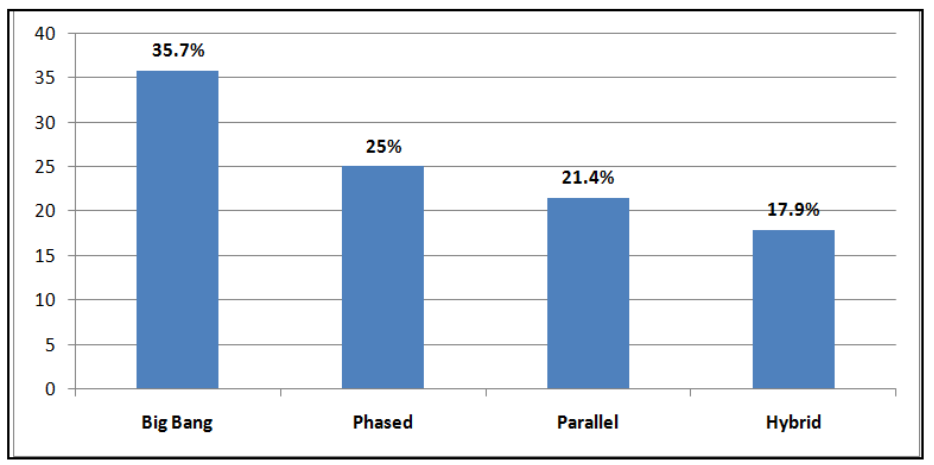

Figure 2: Methodology Used for Implementation

\section{METHODOLOGY}

Table 2: Methodology used for implementation

\begin{tabular}{|c|c|c|c|c|c|}
\hline \multicolumn{2}{|c|}{} & Frequency & Percent & Valid Percent & $\begin{array}{c}\text { Cumulative } \\
\text { Percent }\end{array}$ \\
\hline \multirow{4}{*}{ Valid } & Big Bang & 10 & 35.7 & 35.7 & 35.7 \\
\cline { 2 - 6 } & Phased & 7 & 25.0 & 25.0 & 60.7 \\
\cline { 2 - 6 } & Parallel & 6 & 21.4 & 21.4 & 82.1 \\
\cline { 2 - 6 } & Hybrid & 5 & 17.9 & 17.9 & 100.0 \\
\cline { 2 - 6 } & Total & 28 & 100.0 & 100.0 & \\
\hline
\end{tabular}

The Hypothesis $\mathrm{H} 2$ 
H2: ERP systems were implemented using Big Bang methodology

\section{Chi - Square Test}

\begin{tabular}{|l|c|c|c|}
\hline & Value & Df & $\begin{array}{c}\text { Asymp. } \\
\text { Sig } \\
\text { (2-Sided) }\end{array}$ \\
\hline Pearson Chi-Square & $\mathbf{9 . 5 8 1}$ & 3 & $\mathbf{0 . 0 4 4}$ \\
\hline Likelihood Ratio & $\mathbf{1 1 . 2 3 1}$ & $\mathbf{3}$ & .009 \\
\hline Linear by Linear Association & $\mathbf{4 . 4 7 4}$ & $\mathbf{1}$ & .009 \\
\hline Number of Valid Cases & $\mathbf{2 8}$ & & \\
\hline
\end{tabular}

The Chi - Square test gives the Pearson Chi-Square value of 9.581 at 3 degrees of freedom and the level of significance is 0.044 which is less than 0.05 . Since the $\mathrm{p}$ value is less than 0.05 ie. $\mathrm{P}<0.05$, the null hypothesis is rejected and the research hypothesis is accepted. Therefore Big Bang methodology was used to implement ERP systems in the companies. The Second hypothesis is proved true

\section{VENDORS}

Vendors are community who build up ERP packages. They are the people who have put in large quantity of money, time and effort in research and development of ERP solutions. There are many vendors in the marketplace; choice of the correct ERP vendor adds to the victory of the ERP execution. The larger vendor does not for all time denote enhancement. The causes for the option of bigger ones are financial stability, longevity and various spectrums of offerings. Small vendors that are not known may carry increased risks in the area of long term longevity, but they provide better solution in a spectrum of industries. Table 3 shows that SAP is a leading ERP player in the ERP market.

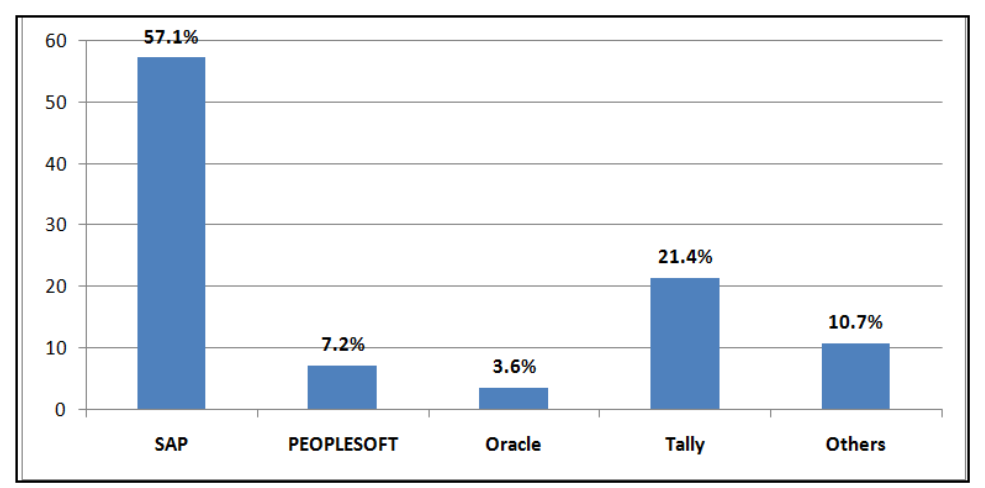

Figure 3: Distribution of Vendors

Table 3: Distribution of vendors

\begin{tabular}{|c|c|c|c|c|c|}
\hline & & Frequency & Percent & $\begin{array}{c}\text { Valid } \\
\text { Percent }\end{array}$ & $\begin{array}{l}\text { Cumulativ } \\
\text { e Percent }\end{array}$ \\
\hline \multirow{6}{*}{ Valid } & SAP & 16 & 57.1 & 57.1 & 57.1 \\
\hline & PEOPLES OF T & 2 & 07.2 & 07.2 & 64.3 \\
\hline & Oracle & 1 & 03.6 & 03.6 & 67.9 \\
\hline & Tally & 6 & 21.4 & 21.4 & 89.3 \\
\hline & Others & 3 & 10.7 & 10.7 & 100.0 \\
\hline & Total & 28 & 100.0 & 100.0 & \\
\hline
\end{tabular}

The Hypothesis H3

SAP is the ERP which is the most preferred in the organizations 


\section{Chi - Square Test}

\begin{tabular}{|c|c|c|c|}
\hline & Value & df & $\begin{array}{l}\text { Asymp. } \\
\text { Sig } \\
\text { (2-Sided) }\end{array}$ \\
\hline Pearson Chi-Square & 15.593 & 4 & 0.000 \\
\hline Likelihood Ratio & 17.019 & 4 & 0.000 \\
\hline Linear by Linear Association & 14.700 & 1 & 0.000 \\
\hline Number of Valid Cases & 28 & & \\
\hline
\end{tabular}

The Chi- Square test gives the Pearson Chi-Square value of 15.593 at 4 degrees of freedom and the level of significance is 0.000 which is less than 0.05 . Since the $\mathrm{p}$ value is less than 0.05 i.e $\mathrm{p}<0.05$, the null hypothesis is rejected and the research hypotheses is accepted. Therefore, H3 is accepted. Therefore, SAP is the most preferred ERP in the mechanical and production organizations.

\section{FINDINGS}

- Implementing ERP in the manufacturing and production units of the organizations improves the customer service and order fulfilment in the company

- Implementing ERP in the manufacturing and production units of the organizations improves the productivity of the company

- $\quad$ Big Bang is the most used methodology in implementing the ERP

- $\quad$ SAP is the most preferred ERP in manufacturing and production organizations.

\section{CONCLUSIONS}

This research aspires to enhance the understanding of the ERP execution and to be aware of its success in South India. As indicated by the study, at present the researcher found that SAP is the real driving Vendor in India. ERP frameworks executed by SMEs have discovered advantages like increment in efficiency, improvement in order fulfillment and interior correspondence additionally expanded because of joint framework and real diminishment in operational expense was watched. The research result shows that organizational fit of ERP impacts execution achievement when the choice of ERP depends on upon comprehended ERP dealers. Owing to the small size of the sample in this study there are also a small number of the speculations of the results to the larger population. ERP implementation is a long term program and may last for a couple of years. In this case a detailed study about the implementation and success are the need of the hour.

\section{REFERENCES}

1. Andre Luiz Pestana de Oliveira; Marco Antonio Pinheiro da Silveira (2010). ERP in the production area: user's opinions about needs being met. JISTEM - Journal of Information Systems and Technology Management. On-line version ISSN $1807-$ 1775.JISTEM J. Inf.Syst. Technol. Manag. (Online) vol.7 no.3 São Paulo 2010. http://dx.doi.org/10.4301/S1807$\underline{17752010000300002}$

2. Daryl Powell, (2013) "ERP systems in lean production: new insights from a review of lean and ERP literature", International Journal of Operations \& Production Management, Vol. 33 Issue: 11/12, pp.14901510, https://doi.org/10.1108/IJOPM-07-2010-0195 
3. Davide Aloini, Riccardo Dulmin, Valeria Mininno, Risk management in ERP project introduction: Review of the literature, Information \& Management, Volume 44, Issue 6, September 2007, Pages 547-567, Elsevier https://doi.org/10.1016/j.im.2007.05.004

4. Jeff K. Stratman, \& Aleda V. Roth (2002) Enterprise Resource Planning (ERP) Competence Constructs: Two-Stage Multi-Item Scale Development and Validation *DOI: 10.1111/j.1540-5915.2002.tb01658.Volume 33, Issue 4, September 2002,Pages 601628

5. Klaus, H., Rosemann, M. \& Gable, G. G. Information Systems Frontiers (2000) $2: \quad 141$. https://doi.org/10.1023/A:1026543906354

6. Moutaz Haddara; Ondrej Zach, System Sciences (HICSS), 2011 44th Hawaii International Conference on 4-7 Jan. 2011 , Print ISBN: 978-1-4244-9618-1, Print ISSN: 1530-1605

7. Aman Deep, Peter Guttridge, Samir Dani, Neil Burns, (2008) "Investigating factors affecting ERP selection in made $\square$ to $\square$ order SME sector", Journal of Manufacturing Technology Management, Vol. 19 Issue: 4, pp.430446, https://doi.org/10.1108/17410380810869905

8. Chwen Sheu, Bongsug Chae, Chen - Lung Yang, National differences and ERP implementation: issues and challenges, https://doi.org/10.1016/j.omega.2004.02.001

9. Valérie Botta-Genoulaz Pierre-AlainMillet, An investigation into the use of ERP systems in the service sector, https://doi.org/10.1016/j.ijpe.2004.12.015 